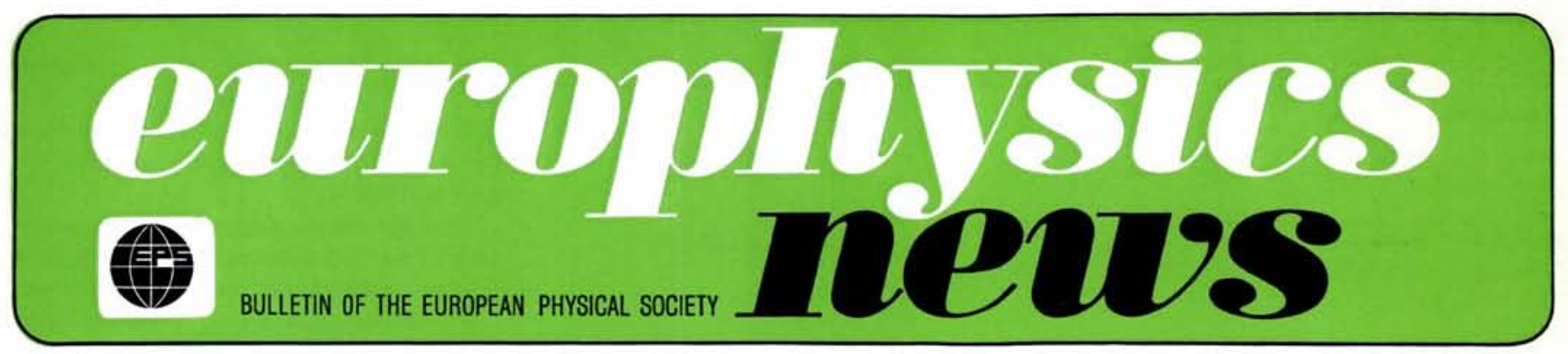

\section{The}

European Great Projects

In Rome on 26-27 March some 250 physicists from a wide range of specializations and from all the countries represented in the European Physical Society, assembled in Rome to listen to lectures on the main projects in physics that will have a strong influence on future developments over the remainder of the century.

This new initiative in bringing together the various branches of physics was recognized as an outstanding success. The lecturers were of high quality - the audience also and the universal consensus was that this must not be an isolated occasion.

Exchanges in the corridors were animated and constructive and if at first, discussions during the formal part of the Seminar were restrained, towards the end, the interaction was beginning to diverge and real issues were being raised that will not be allowed to die. For example: what structure should a centre housing a European Synchrotron Radiation facility have ? Questions such as this are questions of substance that the whole community of physics wants to discuss.

\section{Contents \\ The European Great Projects 1 Fusion Programme of Western Europe \\ Some Large Projects in European Astronomy IRAM \\ UNK \\ LEP \\ European Synchrotron \\ Radiation Facility \\ Albert Einstein \\ More Successes for G? \\ Council Decision: \\ I.O.M. Delegate \\ EPS Scholarships - 3rd List}

\title{
Fusion Programme of Western Europe
}

Some highlights from the paper presented by D. Palumbo, Director of the Fusion Programme within the European Commission's Directorate General for Science, Research and Education.

The cross-section of the D-T reaction (which reaches a maximum of approximately 5 barn at about 100 $\mathrm{keV}$ ) is such that the only way of achieving useful energy generation is by bulk heating of a deuterium-tritium fuel up to temperatures of around $10 \mathrm{keV}$ or $100 \mathrm{MK}$. Elementary considerations of the energy balance lead to the Lawson criterion that for net electrical power production :

$n \tau>[(1-\eta) / \eta]\left[12 k T /<\sigma_{V}>Q_{F}\right]$ where $n$ is the nuclear (and electron) density, $\tau$ is the confinement time, $\langle\sigma v\rangle$ is an average on a maxwellian velocity distribution at a given temperature $T$, and $Q_{F}$ is the energy output per fusion reaction. At a temperature of $10 \mathrm{keV}$ and optimistic conversion efficiency $\eta$, of 0.3 ,

\section{then $\quad n \tau>2 \times 10^{14} \mathrm{~cm}^{-3} \mathrm{~s}$}

The condition of ignition, in which the reacting plasma is heated by the $\alpha$-particles produced, is obtained by putting $\eta=0.2$ in the above relation. Unavoidable radiation losses impose, even for a perfectly confined plasma, a minimum ion temperature of around
4 keV. Impurities of higher atomic number increase this temperature because of the rapid increase in bremsstrahlung radiation with $Z$.

A consequence of the Lawson criterion is that for inertial confinement systems, $n>10^{24} \mathrm{~cm}^{-3}$ and $\tau$ is around $10^{-10} \mathrm{~s}$, whereas for a magnetically confined plasma system, $n \sim 10^{14}$ $10^{15} \mathrm{~cm}^{-3}$ and $\tau$ is of the order of seconds. In inertial confinement, where power densities are about $10^{8}$ $\mathrm{TW} / \mathrm{cm}^{3}$ and pressures $3 \times 10^{10} \mathrm{~atm}$, one has a real micro nuclear explosion and certain States have been reluctant to cooperate internationally on a system which is so close to a military application. As a result, the western European fusion programme has concentrated mainly on magnetic confinement where, with power densities of a few $\mathrm{W} / \mathrm{cm}^{3}$ and pressures of some tens atm, the military implications seem non-existent.

\section{European Coordination}

In the fusion field, cooperation was begun by Euratom, following its foun-

Europhysics News is published monthly by the European Physical Society. (C) 1979. Reproduction rights reserved.

With acknowledgement of this order please send application forms to become an EPS member.

Return this form or a copy to the EPS Secretariat, Geneva. 